\title{
Marshall Islands Pinworm
}

Sindhura Kolli ${ }^{1}$, Sree S. Kolli ${ }^{2}$, Mel A. Ona ${ }^{3}$

1. Internal Medicine, The Brooklyn Hospital Center, New York, USA 2. Medicine, University of Vermont, Burlington, USA 3. Gastroenterology, Pali Momi Medical Center, Honolulu, USA

$\square$ Corresponding author: Sindhura Kolli, sindhura.kolli@gmail.com

Disclosures can be found in Additional Information at the end of the article

\section{Abstract}

Pinworm infections are usually under the spectrum of the Infectious Diseases department, however, they can fall into a gastroenterologist's lap when found incidentally during a screening colonoscopy. This case expands on the epidemiology, clinical presentation, diagnosis, and treatment of pinworms in the patient and household.

Categories: Internal Medicine, Gastroenterology, Infectious Disease

Keywords: pinworm, colonoscopy, enterobius

\section{Introduction}

During screening colonoscopy, a number of pathologies are expected: polyps, ulcers, bleeding, hemorrhoids, and more. Rarely, is a pinworm encountered during a routine screening in an asymptomatic patient. A patient from Marshall Islands, however, surprised the endoscopist both with the presence of a pinworm during a colonoscopy and their asymptomatic presentation. This case demonstrates an incidental pinworm finding and delves into its clinical presentation, diagnosis, and treatment.

\section{Case Presentation}

A 64-year-old female patient from the Marshall Islands presented for a routine average-risk screening colonoscopy for colorectal cancer. She had no presenting symptoms or complaints and had no family history for gastrointestinal malignancy. Vital signs and labs were within normal limits. Colonoscopy demonstrated adequate bowel preparation with Boston Bowel Preparation Score of nine which made for clear visualization of a whitish-colored worm within the cecum (Figure 1). It was retrieved with the cold biopsy forceps and sent for pathology (Figure 2).

Received 04/29/2019

Review began 05/16/2019

Review ended 05/16/2019

Published 05/22/2019

CC Copyright 2019

Kolli et al. This is an open access article distributed under the terms of the Creative Commons Attribution License CC-BY 3.0., which permits unrestricted use, distribution, and reproduction in any medium, provided the original author and source are credited. 


\section{Cureus}

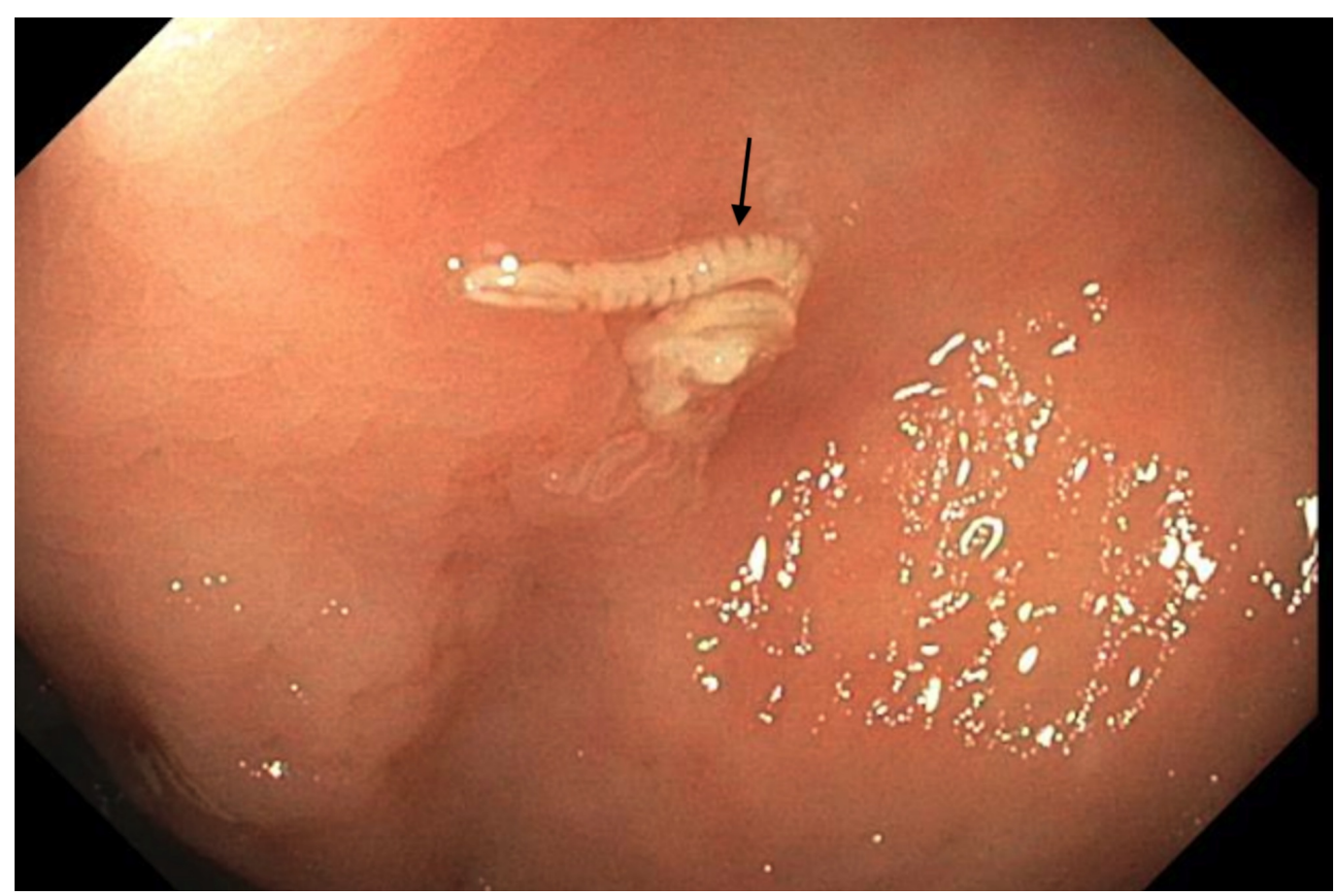

FIGURE 1: Pinworm discovered incidentally during screening colonoscopy.

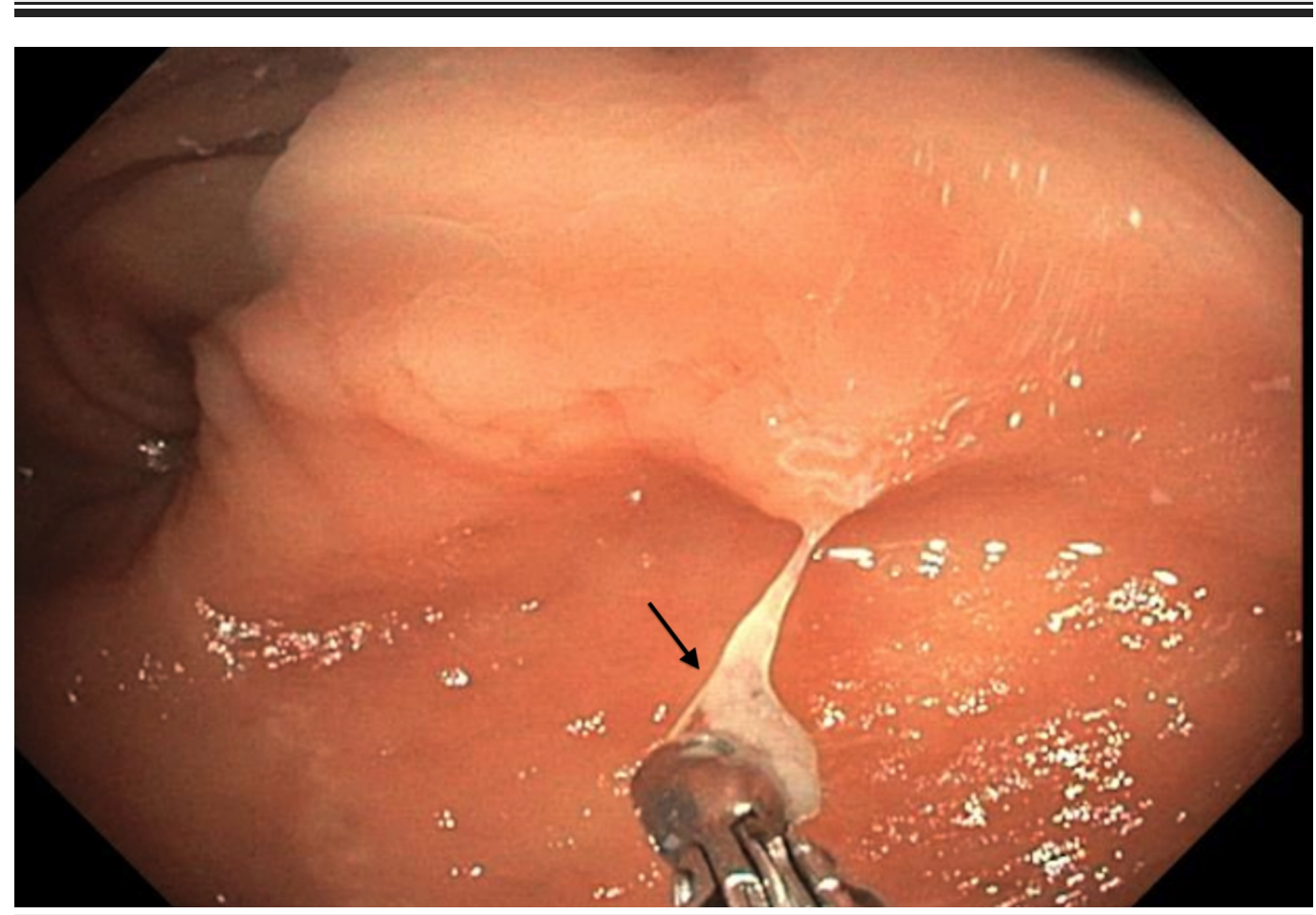

FIGURE 2: Pinworm retrieved with cold biopsy forceps.

Pathology revealed a parasitic organism consistent with pinworm also known as Enterobius vermicularis. Patient was treated with over-the-counter pyrantel pamoate $(11 \mathrm{mg} / \mathrm{kg})$ two doses given two weeks apart. Patient was asymptomatic to begin with and posed no more symptoms or complaints following treatment. 


\section{Discussion}

The prevalence of intestinal parasites is high with estimates of over one billion people affected [1]. The highest prevalence is found in African, Asian, and Latin American countries [2]. Populations most vulnerable to these infections have risk factors such as poor sanitation practices and overcrowding often found in developing countries [1]. People affected in the United States are commonly immigrants from developing countries or have a compromised immune system [3].

Enterobius vermicularis or pinworm is the most common helminth infection in the United States [4]. Pinworms are easily transmissible between those living in close quarters, sharing clothing or sleeping spaces [1]. Pinworm eggs are ingested and proceed to hatch in the small intestine [1]. The larvae migrate to the large intestine and are found primarily in the cecum and appendix [1]. Adult females mature and travel to the perianal region at night laying eggs and infecting clothes, sheets, and fingernails following intense pruritus in perianal region [1]. About $30 \%$ of infected patients exhibit symptoms with clinical presentations include pruritus ani and appendicitis [5-6]. Our patient was asymptomatic possibly because the larvae had not yet migrated to the perineal region and was not situated near the appendix. Diagnosis in symptomatic patients is usually done by placing a piece of Scotch tape in the perianal region at night or early morning and then placed on a glass slide to visualize eggs under a microscope or microscopy of samples taken from under fingernails. Stool samples are not recommended as eggs and worms are generally minimal in stool and serology tests are not available for pinworm [1]. The diagnosis in our asymptomatic patient was made incidentally when the pinworm was visualized during a screening colonoscopy. Treatment of pinworm is with overthe-counter pyrantel pamoate or with a prescription of mebendazole or albendazole. Usually two doses are administered two weeks apart in order to broaden coverage for newly hatched eggs within the two week span. Treatment is recommended for the close contacts in households and work institutions as well [7].

\section{Conclusions}

During a routine colonoscopy, anything should be expected and appropriately dealt with it. In this case, an incidental pinworm in a completely asymptomatic patient was demonstrated, which initiated prompt treatment with a cheap over-the-counter medication to both the patient and her household preventing a transmissible disease from spreading. It reminds every endoscopist to be prepared to find anything during a routine colonoscopy.

\section{Additional Information}

\section{Disclosures}

Human subjects: Consent was obtained by all participants in this study. Brooklyn Hospital Center IRB Board issued approval n/a. Thank you for submitting the Publication materials for this project. The Brooklyn Hospital Center IRB has APPROVED your submission. No further action on this submission is required at this time. The following items are acknowledged in this submission: • Abstract/Summary-IRBPinworm • ApplicationForm-CaseReportApplication • ConsentForm-CaseReportConsent If you have any questions, please contact Twyla Tate at 718250-6947 or ttate@tbh.org. Please include your project title in all correspondence with this committee. . Conflicts of interest: In compliance with the ICMJE uniform disclosure form, all authors declare the following: Payment/services info: All authors have declared that no financial support was received from any organization for the submitted work. Financial relationships: All authors have declared that they have no financial relationships at present or within the previous three years with any organizations that might have an interest in the submitted work. Other relationships: All authors have declared that there are no other relationships or activities that could appear to have influenced the submitted work. 


\section{Cureus}

\section{References}

1. Hechenbleikner EM, McQuade JA: Parasitic colitis. Clin Colon Rectal Surg. 2015, 28:79-86. 10.1055/s-0035-1547335

2. Harhay MO, Horton J, Olliaro PL: Epidemiology and control of human gastrointestinal parasites in children. Expert Rev Anti Infect Ther. 2010, 8:219-234. 10.1586/eri.09.119

3. Polage CR, Stoddard G, Rolfs R, Petti C: Physician use of parasite tests in the United States from 1997 to 2006 and in a Utah Cryptosporidium outbreak in 2007. J Clin Microbiol. 2011, 49:591-596. 10.1128/JCM.01806-10

4. Lohiya GS, Tan-Figueroa L, Crinella FM, Lohiya S: Epidemiology and control of Enterobiasis in a developmental center. West J Med. 2000, 172:305-308.

5. Zakaria OM, Zakaria HM, Daoud MY, et al.: Parasitic infestation in pediatric and adolescent appendicitis: a local experience. Oman Med J. 2013, 28:92-96. 10.5001/omj.2013.25

6. Rawla P, Sharma S: Enterobius vermicularis (pinworm). StatPearls. 2019, Accessed: May 16, 2019: https://www.ncbi.nlm.nih.gov/books/NBK536974/.

7. Caldwell JP: Pinworms (Enterobius vermicularis). Can Fam Phys. 1982, 28:306-309. 